\title{
Percutaneous Endoscopic Surgery for Lumbar Discal Cyst: Two Case Reports
}

\author{
Shiqi Suo a, Yanan Chen ${ }^{a}$, Xirui $\mathrm{Mao}^{\mathrm{a}}$, Song Chen ${ }^{\mathrm{a}}$,, Zhian $\mathrm{Fu}^{\mathrm{a}}$
}

\begin{abstract}
Discal cyst is a rare disease, the pathogenesis is not yet clear and its symptoms are very similar to lumbar disc herniation. Although some cases may regress spontaneously, most cases of lumbar discal cysts are treated surgically. At present, there is no consensus on the treatment of this disease. The authors report the clinical usefulness of the percutaneous endoscopic transforaminal surgery technique in two patients with the lumbar 4-5 discal cyst. The clinical symptoms of both patients were unilateral lower extremity pain and lower back pain. Magnetic resonance imaging of the lumbar spine revealed lumbar discal cysts, causing compression to the spinal dura and roots. Both patients received conservative treatment for more than 6 months, but the clinical symptoms persisted so surgical treatment by percutaneous endoscopic transforaminal surgery without additional discectomy was performed under local anesthesia. The symptoms were relieved immediately after removal of the discal cysts. Postoperative magnetic resonance imaging showed that both patients had complete excision of discal cysts and complete decompression of the treated segmental. There were no recurrent lesions and complications during the follow-up period. We believe that percutaneous transforaminal endoscopic surgery could be a safe, mini-invasive and appropriate method for the treatment of discal cysts.
\end{abstract}

Keywords: Lumbar; Discal cyst; Endoscopy; Minimally invasive

\section{Introduction}

Discal cyst is a rare disease, usually occurs in young people, which can lead to low back pain and radiculopathy [1]. At present, many different kinds of treatment methods have been reported, including analgesia control, computed tomography (CT)-guided cyst aspiration, physical therapy and endoscopic cyst resection. However, a standard surgical treatment method

Manuscript submitted April 17, 2020, accepted May 18, 2020

Published online May 28, 2020

aDepartment of Orthopedics, Affiliated Hospital of Hebei University of Engineering, Handan 056002, China

${ }^{b}$ Corresponding Author: Song Chen, Department of Orthopedics, Affiliated Hospital of Hebei University of Engineering, No. 81 Congtai Road, Handan 056002, China. Email: chensong@hebeu.edu.cn

doi: https://doi.org/10.14740/jmc3474 has not yet been established [2-4]. Percutaneous endoscopic lumbar discectomy (PELD) is a minimally invasive surgical technique, especially to preserve paraspinal structures and avoid back muscle damage [5]. In this study, we have retrospectively reviewed the clinical results of percutaneous transforaminal endoscopic surgery for lumbar discal cysts in two very active young male patients.

\section{Case Reports}

\section{Case 1}

A 24-year-old male college student complained of 11 months of low back pain and 8 months of left lower extremity radicular pain in an L5 distribution. Neurological examination demonstrated a positive straight leg raising sign at $40^{\circ}$ on the left side. There was an objective weakness of the left tibialis anterior and extensor pollicis longus graded as 4. Lumbar radiographs were normal, with no spinal segmental instability and deformity. Magnetic resonance imaging (MRI) revealed a cystic lesion adjacent to the L4-L5 intervertebral disc on the left side, with marked compression of the spinal cord thecal sac and left L5 root. The lesion showed low signal intensity on T1-weighted images and high signal intensity on T2-weighted images, suggesting a cystic lesion (Fig. 1a-c). The CT scan showed disc bulging with no calcification. Before he was admitted, he had received conservative treatment including bed rest, pain control with analgesic and physical therapy for more than half a year. The symptoms had not improved after conservative treatment, and the patient and his family were willing to undertake minimally invasive treatment. We performed a percutaneous transforaminal endoscopic surgery for the discal cyst. The symptoms were relieved immediately after surgery, and there were no intraoperative and postoperative complications. Postoperative MRI showed no remnant of the discal cyst (Fig. 1d). Histopathological examination identified the cyst wall that revealed fibrous connective tissue without lining cells. There were no recurrent lesions during a follow-up period of 12 months.

\section{Case 2}

A 29-year-old male construction worker presented with low back pain radiating to the right lower limb after heavy physical work. Neurological examination demonstrated a positive 

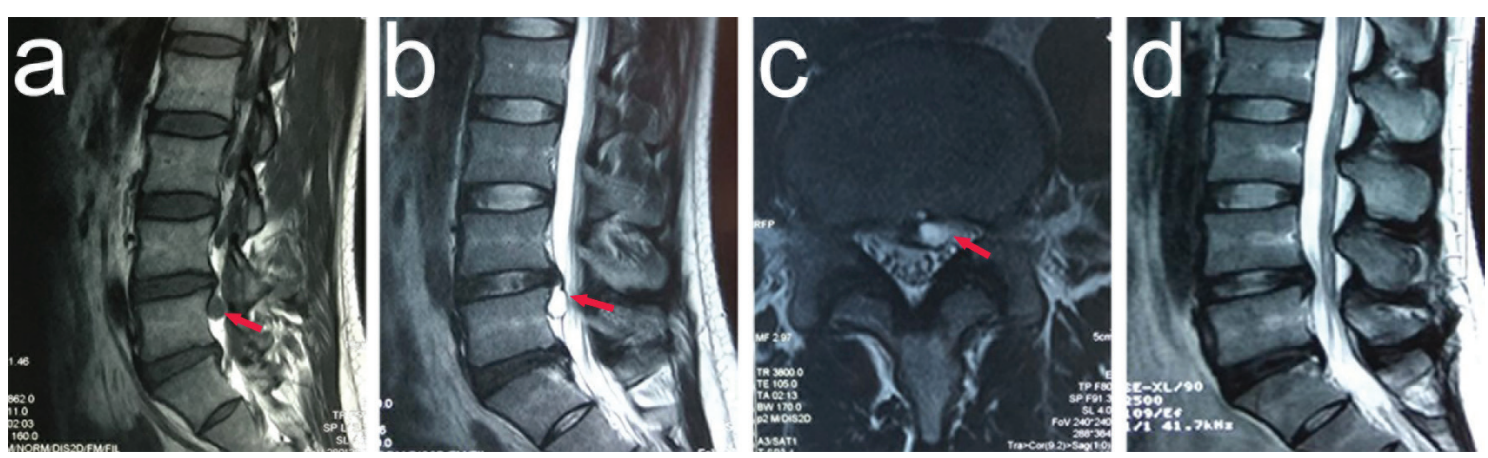

Figure 1. Lumbar spinal MRI of the patient demonstrating the L4-L5 discal cyst, with prominent compression of the left L5 nerve root. (a) Sagittal T1-weighted image shows an ovoid lesion with low signal intensity (red arrow). (b) Sagittal T2-weighted image shows an ovoid lesion with a hyperintense center plus hypointense rim (red arrow). (c) Axial MRI shows the lesion (red arrow). (d) Lumbar T2-weighted MRI shows no residual cyst. MRI: magnetic resonance imaging.

straight leg raising sign at $45^{\circ}$ on the right side. Lumbar radiographs were normal, with no spinal segmental instability and deformity. MRI demonstrated an intraspinal extradural spaceoccupying lesion just caudal to the L4-L5 intervertebral disc on the right side. The lesion showed low signal intensity on T1-weighted images and high signal intensity on T2-weighted images (Fig. 2a, b). He was treated conservatively at his first visit because the symptoms were relatively mild. He continued to work while taking non-steroidal anti-inflammatory drugs and physiotherapy. After 6 months of conservative treatment, the patient's symptoms had not improved and worsened gradually, and repeated MRI images showed persistent cystic structures but no change in size. As the patient was a very active worker, we recommend minimally invasive surgery to avoid back muscle injury. At this time, the patient was willing to undertake the percutaneous transforaminal endoscopic surgery for the discal cyst. Under the endoscope, the cyst wall was attached to the disc. Postoperative MRI showed no remnant of the discal cyst (Fig. 2c). The symptoms were relieved immediately after surgery, and there were no intraoperative and postoperative complications. Histopathological examination identified dense fibro collagenous connective tissue, no synovial lining cells and no intervertebral disc material. There were no recurrent lesions and complications during the 1-year follow-up period.

\section{Discussion}

Discal cyst is an extradural cyst, which usually adheres to the corresponding disc. At present, several hypotheses about the pathogenesis of discal cysts have been reported [6, 7]; however, its specific pathogenesis remains controversial [8]. In both cases, the histopathology result of the tissue resected during the operation was fibrous connective tissue. According to the results of preoperative imaging examination and intraoperative findings, we consider that the pathogenesis of discal cysts formation is closely related to disc herniation, supporting the view of Kono et al [7]. Discography is often used for diagnosis of discal cysts, but it is an invasive procedure that can cause injection-related pain reactions. Neither of both patients underwent discography or CT discography.

Treatments for disc cysts include conservative treatment and surgical treatment. Conservative treatments include rest, pain control, physical therapy, selective nerve root block, etc. [4]. Surgical treatments of discal cysts include microcystectomy, CT-guided cyst aspiration and endoscopic cystectomy $[3,4,9,10]$. Although percutaneous CT-guided puncture and steroid injection has been reported in the treatment of discal cysts $[2,11]$. However, it is reported that there is still the possibility of recurrence after CT-guided puncture and aspiration
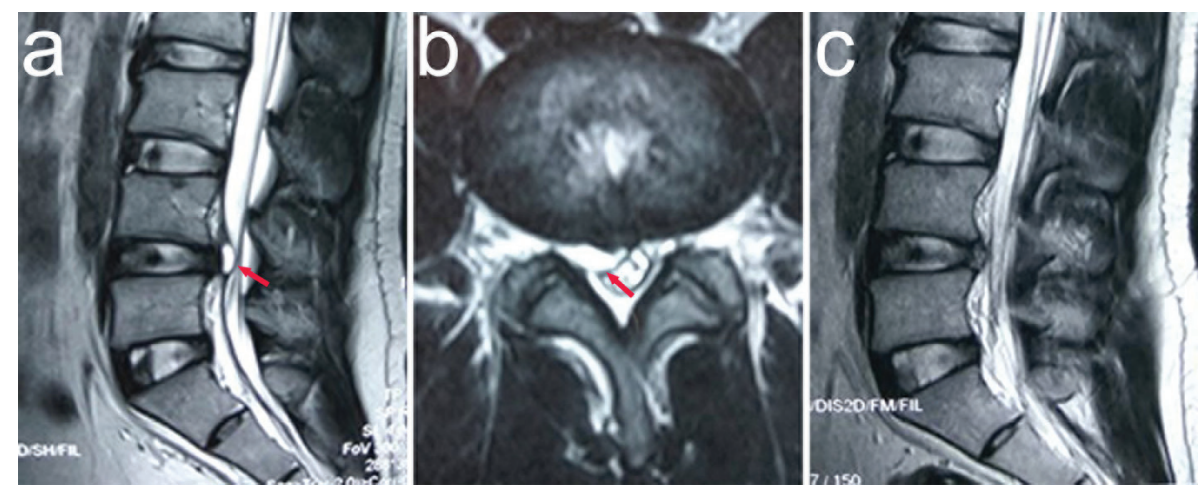

Figure 2. Lumbar spinal MRI of the patient demonstrating the L4-L5 discal cyst, with prominent compression of the right L5 nerve root. (a) Sagittal T2-weighted image shows an ovoid lesion with a hyperintense center plus hypointense rim (red arrow). (b) Axial MRI shows the lesion (red arrow). (c) Lumbar T2-weighted MRI shows no residual cyst. MRI: magnetic resonance imaging. 
$[3,12]$. Therefore, we prefer to perform radical resection of discal cysts.

When the discal cyst was removed during the operation, it is necessary to confirm the stalk between the disc and the capsule of the discal cyst. Excision of the capsule of the discal cyst and the stalk of the disc is the key step to ensure the success of the operation. During the operation, it can be observed under the endoscope that the adhesion between the discal cyst and the intervertebral disc is serious. In both cases, we removed the subligamentous herniation of the disc directly connected to the cyst and did not perform the discectomy. It has been reported that the corresponding intervertebral disc should be removed when removing the discal cyst, and more thorough resection might reduce the risk of postoperative recurrence [3, 13]. However, some related studies reported only resection of the discal cyst without corresponding discectomy, the surgical effect was good and the postoperative follow-up showed no recurrence [14]. We believe that whether or not to perform the corresponding discectomy requires careful consideration. Discal cysts commonly occur in young people, and the corresponding discectomy will have an impact on their spinal biomechanics. It has been reported that minimally invasive discectomy may lead to spinal instability [15]. For this reason, we chose to remove the discal cyst alone without corresponding discectomy. There was no cyst recurrence in both patients after operation. According to our surgical experience and clinical results, we consider that only removal of the cyst may be an effective method for the treatment of lumbar discal cysts.

\section{Conclusion}

Percutaneous transforaminal endoscopic surgery could be a safe, minimally invasive surgical treatment for the discal cyst, particularly suitable for young patients with high activity requirements. In addition, PELD could be considered as an appropriate alternative therapy for the discal cyst by preserving normal anatomic structures.

\section{Acknowledgments}

None to declare.

\section{Financial Disclosure}

None to declare.

\section{Conflict of Interest}

The authors declare that they have no conflict of interest.

\section{Informed Consent}

Written consent was obtained from the patient.

\section{Author Contributions}

SC and SQS carried out the whole studies, participated in the sequence alignment and wrote the article; YNC and ZAF were involved in the reference collection, and SC gave the final approval.

\section{Data Availability}

The authors declare that data supporting the findings of this study are available within the article.

\section{References}

1. Kim SY. Radiculopathy caused by discal cyst. Korean J Pain. 2014;27(1):86-89.

2. Haider SJ, Na NR, Eskey CJ, Fried JG, Ring NY, Bao $\mathrm{MH}$, Pastel DA. Symptomatic lumbar facet synovial cysts: clinical outcomes following percutaneous CTguided cyst rupture with intra-articular steroid injection. J Vasc Interv Radiol. 2017;28(8):1083-1089.

3. Jha SC, Higashino K, Sakai T, Takata Y, Abe M, Nagamachi A, Fukuta S, et al. Percutaneous endoscopic discectomy via transforaminal route for discal cyst. Case Rep Orthop. 2015;2015:273151.

4. Arslan E, Demirci I, Simsek G, Kilincaslan MO, Guresci S, Hacifazlioglu C. Which treatment method should be preferred for lumbar discal cysts? A case report and a review of the literature. Neurol Neurochir Pol. 2014;48(1):71-75.

5. Sairyo K, Chikawa T, Nagamachi A. State-of-the-art transforaminal percutaneous endoscopic lumbar surgery under local anesthesia: Discectomy, foraminoplasty, and ventral facetectomy. J Orthop Sci. 2018;23(2):229-236.

6. Chiba K, Toyama Y, Matsumoto M, Maruiwa H, Watanabe M, Nishizawa T. Intraspinal cyst communicating with the intervertebral disc in the lumbar spine: discal cyst. Spine (Phila Pa 1976). 2001;26(19):2112-2118.

7. Kono K, Nakamura H, Inoue Y, Okamura T, Shakudo M, Yamada R. Intraspinal extradural cysts communicating with adjacent herniated disks: imaging characteristics and possible pathogenesis. AJNR Am J Neuroradiol. 1999;20(7):1373-1377.

8. Bruder M, Cattani A, Gessler F, Droste C, Setzer M, Seifert V, Marquardt G. Synovial cysts of the spine: longterm follow-up after surgical treatment of 141 cases in a single-center series and comprehensive literature review of 2900 degenerative spinal cysts. J Neurosurg Spine. 2017;27(3):256-267.

9. Dasenbrock HH, Kathuria S, Witham TF, Gokaslan ZL, Bydon A. Successful treatment of a symptomatic L5/S1 discal cyst by percutaneous CT-guided aspiration. Surg Neurol Int. 2010;1:41.

10. Gadjradj PS, Harhangi BS. Percutaneous Transforaminal Endoscopic Discectomy for Lumbar Disk Herniation. Clin Spine Surg. 2016;29(9):368-371. 
11. Friedman MV, Park A, Bumpass D, Jennings JW, Matava MJ. Percutaneous discal cyst rupture in a professional football player using sublaminar epidural injection for thecal sac displacement. J Vasc Interv Radiol. 2015;26(1):75-78.

12. Aydin S, Abuzayed B, Yildirim H, Bozkus H, Vural M. Discal cysts of the lumbar spine: report of five cases and review of the literature. Eur Spine J. 2010;19(10):16211626 .

13. Kim JS, Choi G, Jin SR, Lee SH. Removal of a discal cyst using a percutaneous endoscopic interlaminar approach: a case report. Photomed Laser Surg. 2009;27(2):365-369.

14. Park JW, Lee BJ, Jeon SR, Rhim SC, Park JH, Roh SW. Surgical treatment of lumbar spinal discal cyst: is it enough to remove the cyst only without following discectomy? Neurol Med Chir (Tokyo). 2019;59(6):204-212.

15. Banczerowski P, Czigleczki G, Papp Z, Veres R, Rappaport HZ, Vajda J. Minimally invasive spine surgery: systematic review. Neurosurg Rev. 2015;38(1):11-26; discussion 26. 